\title{
Structural, dielectric, piezoelectric and ferroelectric behavior of rare earth double doped lead titanate ceramics synthesized by solid state method
}

\author{
Karan Singh, Vishal Singh, Rashmi Gupta, K. K. Bamzai* \\ Crystal Growth \& Materials Research Laboratory, Department of Physics and Electronics, \\ University of Jammu, Jammu - 180006. (INDIA)
}

\begin{abstract}
Praseodymium and yttrium in equal compositions was doped in lead titanate having general formula $P b_{1-x} P_{x} T i_{1-y} Y_{y} O_{3}$ where $x$ (praseodymium) $=y(y$ ttrium $)=0.02,0.04,0.06$ and 0.08 . These four compositions were synthesized by solid state reaction technique. $X$-ray diffraction analysis confirms single phase formation with perovskite structure having tetragonal phase. Microstructural analysis shows formation of dense microstructure with grain size in the range of $0.38-0.54 \mu \mathrm{m}$. Dielectric behavior as a function of temperature gave the value of Curie temperature. The diffusivity in the dielectric behavior was observed in three different compositions. Piezoelectric coefficient $d_{33}$ showed an increasing trend with increase in compositions of the substituent. The ferroelectric properties were studied at room temperature as a function of composition. The value of remnant polarization $\left(P_{r}\right)$, spontaneous polarization $\left(P_{s}\right)$ and coercive field was determined.
\end{abstract}

Keywords: Ceramics, Dielectric, Ferroelectric, Lead titanate, Solid State Reaction

\section{Introduction}

Ferroelectric oxides having perovskite structure with general formula $\mathrm{ABO}_{3}(\mathrm{~A}=$ monovelent or diavalent, $\mathrm{B}=$ trivalent or hexavalent ions) are in the forefront both in the areas of research as well as industrial applications. Lead titanate (PT) ceramics modified by rare earth elements and alkaline earth element have emerged as highly promising materials. These modified materials are extremely good for high frequency applications [1]. Pyroelectric lead titanate ceramics have been found useful for use in thermal imaging and human detection [2]. Several dopants have been employed as individual additives, combination doping by two or more dopant ions [3-11] and encouraging results obtained in these systems boosted the research activity in the modified lead titanate ceramics. Successful modification have been achieved by simultaneous addition of 24 mol $\%$ calcium, $2 \mathrm{~mole} \%$ cobalt, 2 mole $\%$ tungsten and 1-2 mol\% $\mathrm{MnO}_{2}$ [3]. Addition of $8 \mathrm{~mole} \%$ of $\mathrm{La}_{2} \mathrm{O}_{3}$ or $24 \mathrm{~mole} \% \mathrm{CaO}$ strongly diminishes Curie temperature and dielectric constant of PT ceramics. Such decrease is more pronounced in case of $\mathrm{CaO}$ addition [4]. Dense and hard ceramics have been prepared by adding suitable dopants or combining with other compounds to form solid solution [5-7]. Chu and Chen [8] have reported reduction in sintering temperature by the addition of perovskite dopants in samarium modified ceramics without affecting dielectric and other anisotropic properties. Reduction in sintering temperature helps in reducing lead losses during sintering. Deb [9] has reported high dielectric constant, high pyroelectric constant and favorable thermal and mechanical characteristics in samarium modified lead titanate ceramics. Doping reduces the Curie temperature for pure lead titanate ceramics which is $490^{\circ} \mathrm{C}$. Dielectric, piezoelectric and ferroelectric properties of samarium modified PT ceramics prepared by solid state reaction method has been studied by Tickoo et al [10] whereas Pr modified PT ceramics was studied by Singh et al [11]. Thus, properties of materials depend both on chemical composition as well as the process of preparation. In the present paper, two different rare earth elements viz., praseodymium and yttrium was used for modification of lead titanate and then to study the influence of dopants on the structural, dielectric, piezoelectric and ferroelectric characterizations. These two rare earth elements are so chosen that praseodymium with ionic radii $1.09 \AA$ replaces lead (1.20 $\AA$ ), whereas yttrium with ionic radii $0.93 \AA$ replaces titanium $(0.90 \AA)$. To the best of author's knowledge, there is no such report on such rare earth double doped lead titanate ceramics.

\subsection{Materials Prepared}

\section{Materials And Methods}

Rare earth (i.e. praseodymium and yttrium) double doped lead titanate having composition $\mathrm{Pb}_{1-\mathrm{x}} \mathrm{Pr}_{\mathrm{x}} \mathrm{Ti}_{1}$ ${ }_{\mathrm{y}} \mathrm{Y}_{\mathrm{y}} \mathrm{O}_{3}$ with $\mathrm{x}($ praseodymium $)=\mathrm{y}(\mathrm{yttrium})=0.02,0.04,0.06$ and 0.08 have been synthesized in the polycrystalline form by solid state reaction method. The formulation was based on the assumption that praseodymium having ionic radii closer to lead will replace it at A-site whereas yttrium will replace titanium on B-site. The composition was prepared according to the above mentioned formula using high purity chemicals of $\mathrm{PbO}(99 \%), \mathrm{Y}_{2} \mathrm{O}_{3}(99.9 \%), \mathrm{TiO}_{2}(99 \%), \mathrm{Pr}_{6} \mathrm{O}_{11}(99.5 \%)$ (S. d. fine Chem Lltd). The starting material was 
weighed as per the stoichiometric formula and mixed thoroughly. Excess of 2-3\% $\mathrm{PbO}$ was added in order to compensate for its vaporization during sintering. Each mixture was milled in ball milling machine for $48 \mathrm{~h}$ using de-ionized water and zirconia balls. The amount of de-ionized water used is enough to form slurry to prevent the selective sedimentation of the reagents. The slurry was then taken out and put into the oven for $2 \mathrm{~h}$ at a temperature of about $150^{\circ} \mathrm{C}$. The prepared material was then sintered at a temperature of $1100^{\circ} \mathrm{C}$ for $2 \mathrm{~h}$.

\subsection{Characterization}

The prepared material was then characterized for structural investigations by X-ray diffraction (XRD) techniques with $\mathrm{CuK} \alpha$ having wavelength $\lambda=1.5406 \AA$. The microstructure was studied using scanning electron microscope (SEM) of JEOL - 840 model. The elemental analysis has been carried out by energy dispersive Xray analysis (EDAX) using an X-ray detector attached to the SEM instrument. The dielectric properties were measured using fully automated impendence analyzer (4192A - LF) interfaced to computer with USB-GPIB converter $82357 \mathrm{~B}$ (Agilent) working in the range of $5 \mathrm{~Hz}$ to $13 \mathrm{MHz}$. For the measurements of dielectric constant as a function of temperature, the sample of thickness 1- $2 \mathrm{~mm}$ and diameter $10-12 \mathrm{~mm}$ were polished with silver electrodes and then fired in an oven up to at $400^{\circ} \mathrm{C}$ for $1 \mathrm{~h}$. The dielectric properties were then measured at different frequencies of $1,5,10,20$, and $50 \mathrm{kHz}$ in the temperature range of $30-500^{\circ} \mathrm{C}$. The polarization versus electric field $(\mathrm{P}-\mathrm{E})$ hysteresis loop was recorded at room temperatures using $\mathrm{P}$ - E loop tracer. The Berlin court meter (PM 300) was used for carrying out piezoelectric measurements like longitudinal piezoelectric constant $\left(\mathrm{d}_{33}\right)$.

\subsection{Structural analysis}

\section{Results And Discussion}

The X-ray diffraction pattern of compositions $\mathrm{Pb}_{1-\mathrm{x}} \mathrm{Pr}_{\mathrm{x}} \mathrm{Ti}_{1-\mathrm{y}} \mathrm{Y}_{\mathrm{y}} \mathrm{O}_{3}$ where $\mathrm{x}=\mathrm{y}=0.02,0.04 .0 .06,0.08$ is shown in Figure 1. The diffraction pattern confirms the tetragonal phase formation as per the ASTM - Cat. No 6-0452. The lattice constants $(a, c)$ of all the compositions were determined using formula $1 / d^{2}=h^{2}+k^{2} / a^{2}+l^{2} / c^{2}$. The crystal tetragonality (c/a) decreases with increase in the praseodymium and yttrium content in the lead titanate as shown in Figure 2. The change in lattice parameter and lattice tetragonality depends upon the ionic radii of the dopant and increase in the ionic radii of the dopant decreases the crystal tetragonality [12]. The experimental density of different composition was calculated from the ratio of mass to volume of the sample, whereas theoretical density $\left(\rho_{\mathrm{th}}\right)$ was calculated using equation:

$\rho_{\text {th }}=\mathrm{Z} \cdot \mathrm{M} / \mathrm{N}_{0} \mathrm{a}^{2} \mathrm{c}$

where ' $\mathrm{Z}$ ' is the number of molecules in a unit cell which for perovskite is $1, \mathrm{~N}$ is Avogadro's number $\left(6.02 \times 10^{23}\right), \mathrm{M}$ is molecular weight of the composition and ' $\mathrm{a}$ ' and ' $\mathrm{c}$ ' are the lattice parameter obtained from the X-ray diffraction pattern. The value of theoretical density decreases from 8.03 to $7.96 \mathrm{~g} / \mathrm{cm}^{3}$. A decrease in the theoretical density with the increases in praseodymium and yttrium content is due to the fact that praseodymium and yttrium replaces lead and titanate ions. This decrease in theoretical density was also observed in modified lead titanate ceramics. The result of theoretical density, experimental density and porosity is given in Table 1. From the table, it is found that relative density increases from $79.8 \%$ to $93.3 \%$, this increase in relative density and decrease in porosity is due to the fact that increase in praseodymium and yttrium content decreases the tetragonality because of reduction of its internal stress. Reduction of internal stress allows the crystallites in grain to accommodate more closely to form a denser microstructure.

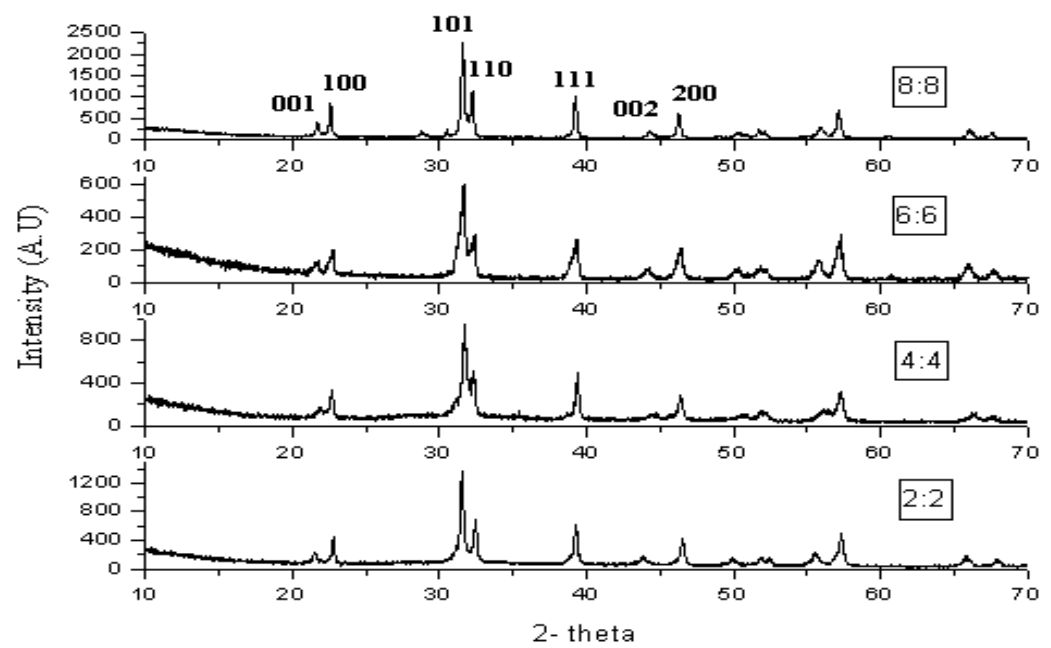

Fig. 1 XRD pattern of the composition $\mathrm{Pb}_{1-\mathrm{x}} \mathrm{Pr}_{\mathrm{x}} \mathrm{Ti}_{1-\mathrm{y}} \mathrm{Y}_{\mathrm{y}} \mathrm{O}_{3}$ where $\mathrm{x}=\mathrm{y}=0.02,0.04 .0 .06,0.08$ 


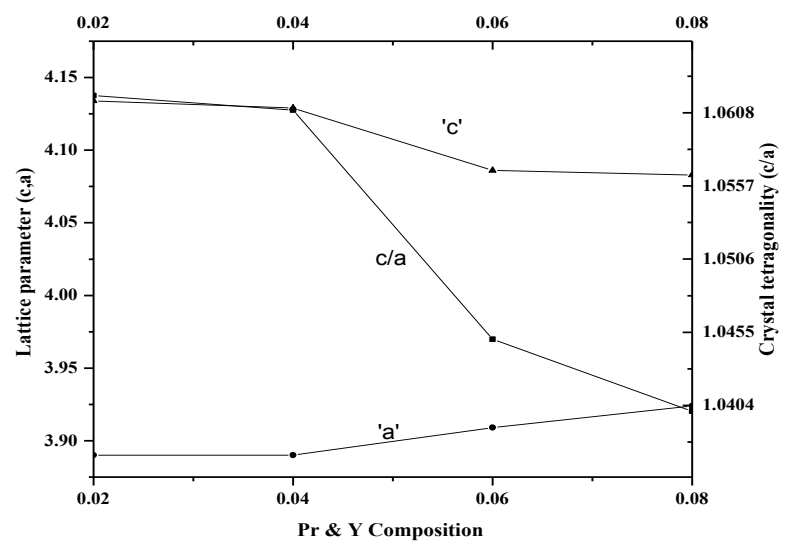

Fig. 2 Variation of crystal lattice and crystal tetragonality

\subsection{Microstructural analysis}

Microstructure is an important parameter that influences the ferroelectric, dielectric, electromechanical and piezoelectric properties. Figure 3(a - d ) shows the microstructure of praseodymium and yttrium doped lead titanate $\mathrm{Pb}_{1-\mathrm{x}} \mathrm{Pr}_{\mathrm{x}} \mathrm{Ti}_{1-\mathrm{y}} \mathrm{Y}_{\mathrm{y}} \mathrm{O}_{3}$ (where $\mathrm{x}=\mathrm{y}=0.02,0.04,0.06,0.08$ ) respectively. The electron micrographs shows well defined grain as well as grain boundary. The grain size determined by the average intercept line (AIL) method was found to decrease with the increase of praseodymium and yttrium content from 0.54 to $0.48 \mu \mathrm{m}$. Table 1 gives a compiled data regarding lattice parameter, theoretical density, experimental density, relative density, porosity and grain size for the double doped rare earth lead titanate ceramics. Figure 4 shows energy dispersive $\mathrm{X}$ - ray analysis (EDAX) of one of the representative graph for praseodymium and yttrium modified lead titanate ceramics of composition $x=y=0.02$. This EDAX results confirms the presences of the required element in the grown material with almost all the peaks associated with the elements are seen in the spectrum such as lead, yttrium, praseodymium, titanium etc.
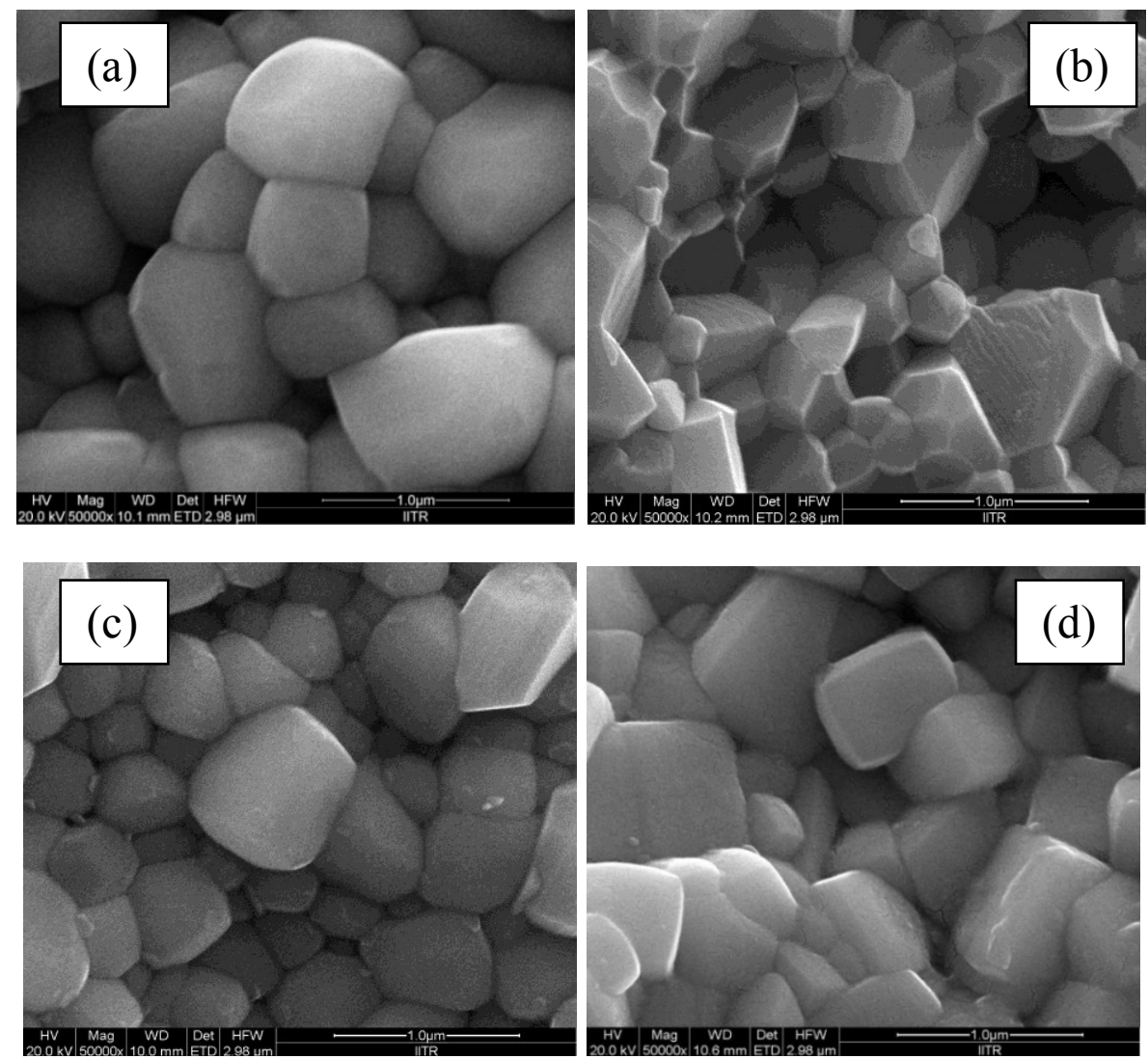

Fig. 3 Scanning electron microscopic images for rare earth double doped lead titanate with composition (a) $x=y=2 \%$, (b) $x=y=4 \%$, (c) $x=y=6 \%$ and (d) $x=y=8 \%$ 


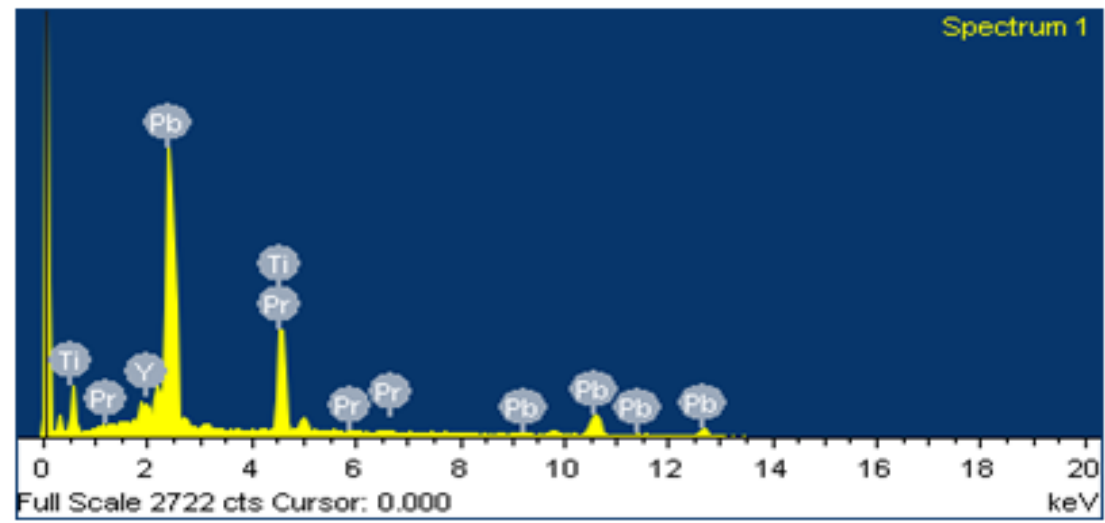

Fig. 4 Energy dispersive X-ray analysis pattern showing the constituent elements present for composition $\mathbf{x}=\mathbf{y}=\mathbf{0 . 0 2}$

Table 1. Lattice constants (a \& c), X-ray density, experimental density, relative density, porosity and grain size for rare earth double doped lead titanate with compositions $\operatorname{Pb}_{1-\mathrm{x}} \operatorname{Pr}_{\mathrm{x}} \operatorname{Ti}_{1-\mathrm{y}} \mathrm{Y}_{\mathrm{y}} \mathrm{O}_{3}$ where $x=y=$ $0.02,0.04,0.06$ and 0.08

\begin{tabular}{|c|c|c|c|c|c|c|c|c|}
\hline $\begin{array}{l}x=P r \\
y=Y\end{array}$ & $c(\AA)$ & $\mathrm{a}(\AA)$ & $\mathrm{c} / \mathrm{a}$ & $\begin{array}{l}\rho_{\mathrm{x}-\mathrm{ray}} \\
(\mathrm{g} / \mathrm{cc})\end{array}$ & $\begin{array}{l}\rho_{\exp } \\
(g / c c)\end{array}$ & $\begin{array}{l}\text { Relative } \\
\text { density (\%) }\end{array}$ & Porosity & $\begin{array}{l}\text { Grain } \\
\text { Size }(\mu \mathrm{m})\end{array}$ \\
\hline $\begin{array}{l}x=0.02 \\
y=0.02\end{array}$ & 4.134 & 3.890 & 1.062 & 8.0366 & 6.415 & 79.82 & 20.17 & 0.54 \\
\hline $\begin{array}{l}x=0.04 \\
y=0.04\end{array}$ & 4.129 & 3.890 & 1.061 & 8.0350 & 6.994 & 87.05 & 12.94 & 0.38 \\
\hline $\begin{array}{l}x=0.06 \\
y=0.06\end{array}$ & 4.086 & 3.909 & 1.452 & 8.0282 & 7.166 & 89.26 & 11.77 & 0.46 \\
\hline $\begin{array}{l}x=0.08 \\
y=0.08\end{array}$ & 4.083 & 3.924 & 1.040 & 7.9640 & 7.434 & 93.33 & 6.65 & 0.48 \\
\hline
\end{tabular}

\subsection{Dielectric Behavior}

The study of dielectric is an important experimental tool to understand the electrical behavior of a given material. The behavior of dielectric constant for rare earth double doped lead titanate was studied in the temperature range of $30-500^{\circ} \mathrm{C}$ by varying frequencies viz. 1, 5, 10 and $50 \mathrm{kHz}$. Figure $5(\mathrm{a}-\mathrm{d})$ shows the behavior of dielectric constant with temperature at different frequencies for four different compositions. From the figure, it is observed that for all compositions up to a temperature of $200^{\circ} \mathrm{C}$, the value of dielectric constant does not shows any substantial change. From 200 to $300^{\circ} \mathrm{C}$, the value of dielectric constant shows some increase in the values and thereafter the value increases abruptly, attains a maximum value and then decreases with further increase in temperature. The temperature at which dielectric constant attains the maximum value gives Curie temperature $\left(\mathrm{T}_{\mathrm{C}}\right)$ for these compositions. The maximum value of dielectric constant and Curie temperature is given in the Table 2. The maximum value of dielectric constant increases from 2178 in case of $x=y=0.02$ to 5440 in case of $x=y=0.08$ except for $x=y=0.06$, where the dielectric constant shows a value of 1202. The increase in dielectric constant with temperature takes place because polarization is inherent property of ferroelectrics and the electron transfer increases due to thermally activated electrons. The electron exchange in ferroelectrics is due to local displacement of charges in the direction of applied field, which determines the polarization of the phases. The increase in dielectric constant can be understood by possible formation of smaller crystallite size which in turn result as good grain connectivity and high density [13] which is further helpful in easy transfer of electrons which forms electric dipoles. 


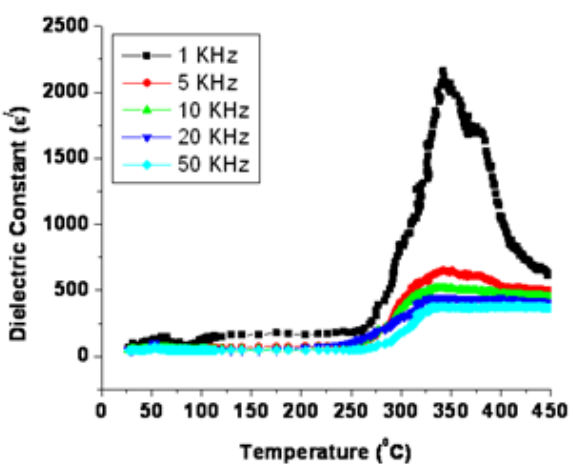

(a)

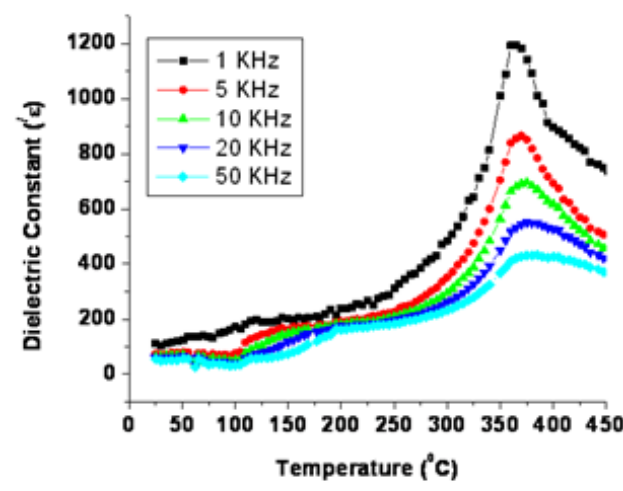

(c)

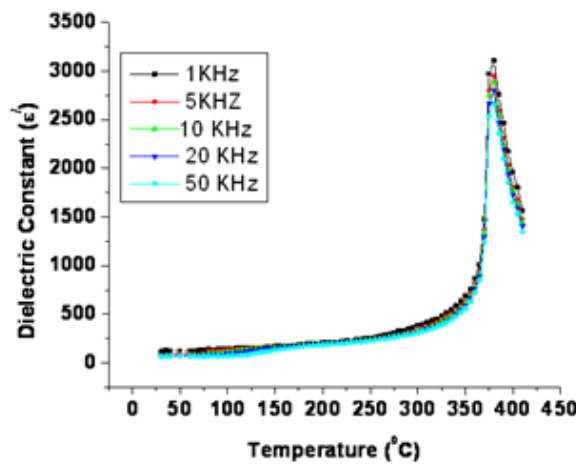

(b)

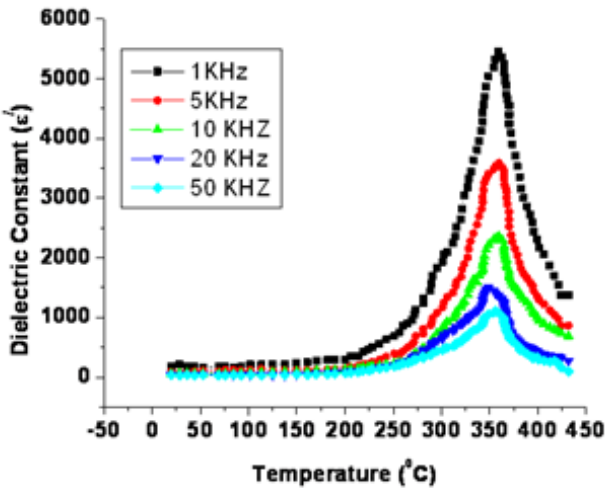

(d)

Fig. 5 Variation of dielectric constant versus temperature for rare earth double doped lead titanate with composition (a) $x=y=2 \%$, (b) $x=y=4 \%$, (c) $x=y=6 \%$ and (d) $x=y=8 \%$

From the figure, it has been found that there is a diffused phase transition from ferroelectric to paraelectric except in case of $x=y=0.04$. From Figure 5(b), the behavior of dielectric constant with temperature in case of $\mathrm{x}=\mathrm{y}=0.04$ clearly shows the sharp transition peak which however is not found for other composition. This broadening of dielectric peak is considered to be because of disorder in the arrangement of rare earth with other atoms leading to microscopic heterogeneity. The degree of diffusivity $(\gamma)$ can be calculated using the expression [14]:

$$
\ln \left(1 / \varepsilon^{\prime}-1 / \varepsilon_{\max }^{\prime}\right)=\gamma \ln \left(\mathrm{T}-\mathrm{T}_{\mathrm{C}}\right)+\mathrm{C}
$$

where ' $\varepsilon$ ' ${ }_{\max }^{\prime}$ ' is the maximum value of dielectric constant at transition temperature, ' $\gamma$ ' is the degree of diffusiveness which lies in the range $1<\gamma \leq 2 . \gamma=1$ represent the ideal Curie Weiss behavior, whereas ' $\gamma$ ' between 1 and 2 indicates diffuse phase transition [15]. The value of ' $\gamma$ ' is calculated from the slope of graph $\ln$ $\left(1 / \varepsilon^{\prime}-1 / \varepsilon_{\max }^{\prime}\right)$ versus $\ln \left(\mathrm{T}-\mathrm{T}_{\mathrm{C}}\right)$. In case of $\mathrm{x}=\mathrm{y}=0.02,0.06$ and 0.08 the value comes out to be $1.56,1.30$ and 1.54 respectively, thereby suggesting the presence of voids. However, in case of $x=y=0.04$, the value comes out to be 1.09, which represent the ideal Curie Weiss behavior.

Table 2 Values of dielectric constant, Curie temperature, piezoelectric coefficient $\left(d_{33}\right.$ and $\left.g_{33}\right)$ for rare earth double doped lead titanate with compositions $\operatorname{Pb}_{1-\mathrm{x}} \operatorname{Pr}_{\mathrm{x}} \mathrm{Ti}_{1-\mathrm{y}} \mathrm{Y}_{\mathrm{y}} \mathrm{O}_{3}$ where $\mathrm{x}=\mathrm{y}=0.02,0.04,0.06$ and 0.08

\begin{tabular}{|c|c|c|c|c|}
\hline $\begin{array}{c}\text { Compositions } \\
\begin{array}{c}\mathrm{x}=\mathrm{Pr} \\
\mathrm{y}=\mathrm{Y}\end{array}\end{array}$ & $\begin{array}{c}\text { Dielectric } \\
\text { constant }\left(\varepsilon^{\prime}\right)\end{array}$ & $\begin{array}{c}\text { Curie } \\
\text { Temperature } \\
\left({ }^{0} \mathrm{C}\right)\end{array}$ & $\begin{array}{c}\text { Piezoelectric } \\
\text { charge Coefficient } \\
\left(\mathrm{d}_{33}\right)\left({ }_{\mathrm{p}} \mathrm{c} / \mathrm{N}\right)\end{array}$ & $\begin{array}{l}\text { Piezoelectric } \\
\text { voltage Coefficient } \\
\left(\mathrm{g}_{33}\right)\left(\times 10^{-3} \mathrm{Vm} / \mathrm{N}\right)\end{array}$ \\
\hline $\begin{array}{l}x=0.02 \\
y=0.02\end{array}$ & 2178 & 345 & 26 & 13 \\
\hline $\begin{array}{l}x=0.04 \\
y=0.04\end{array}$ & 3109 & 380 & 32 & 11 \\
\hline $\begin{array}{l}x=0.06 \\
y=0.06\end{array}$ & 1202 & 366 & 35 & 32 \\
\hline $\begin{array}{l}x=0.08 \\
y=0.08\end{array}$ & 5440 & 361 & 54 & 11 \\
\hline
\end{tabular}


Structural, dielectric, piezoelectric and ferroelectric behavior of rare earth double doped ....

\subsection{Piezoelectric properties}

Piezoelectric charge coefficient $\left(\mathrm{d}_{33}\right)$ show dependence on rare earth double doped lead titanate. The longitudinal piezoelectric charge coefficient $\left(\mathrm{d}_{33}\right)$ for four different compositions i.e., $\mathrm{x}=\mathrm{y}=0.02,0.04,0.06$ and 0.08 comes out be $26,32,35$ and $54 \mathrm{pC} / \mathrm{N}$ respectively. The increase in $\mathrm{d}_{33}$ value is suggested due to the reorientation of domain, which is facilitated by decrease in crystal tetragonality [16]. The piezoelectric voltage coefficient $\left(\mathrm{g}_{33}\right)$ was calculated using the expression: $\mathrm{g}_{33}=\mathrm{d}_{33} / \varepsilon_{0} \varepsilon^{\prime}$, where $\varepsilon_{0}$ is the permittivity of free space $\left(\varepsilon_{0}\right.$ $=8.9 \times 10^{-12}$ farads/meter) and $\varepsilon^{\prime}$ is the dielectric constant of the materials. The maximum value of piezoelectric voltage coefficient was found to be $32 \times 10^{-3} \mathrm{Vm} / \mathrm{N}$ in case of $\mathrm{x}=\mathrm{y}=0.06$ mole $\%$. Table 2 gives the compile data regarding maximum value of dielectric constant, Curie temperature, piezoelectric charge coefficient and piezoelectric voltage coefficient.

\subsection{Ferroelectric properties}

In order to confirm the ferroelectric behavior, polarization versus electric field (P - E) loops was observed for all the composition of praseodymium and yttrium modified lead titanate ceramics. The hysteresis loops were recorded at room temperature. Figures $6(\mathrm{a}-\mathrm{d})$ shows the $(\mathrm{P}-\mathrm{E})$ loops of 2, 4, 6 and 8 mole $\%$ of $\mathrm{Pr}$ and Y substitution respectively. As is seen from the hysteresis curves, it is evident that $\operatorname{Pr}$ and $\mathrm{Y}$ substitution effects values of the spontaneous polarization $\left(\mathrm{P}_{\mathrm{s}}\right)$, coercive field $\left(\mathrm{E}_{\mathrm{c}}\right)$ and remnant polarization $\left(\mathrm{P}_{\mathrm{r}}\right)$ and their respective values are presented in Table 3. It is observed that remnant polarization $\left(\mathrm{P}_{\mathrm{r}}\right)$ first decreases for $x=y=$ 0.04 composition, increases a bit for $\mathrm{x}=\mathrm{y}=0.04$ and then gives a maximum value of $6.92 \mu \mathrm{C} / \mathrm{cm}^{2}$ for $\mathrm{x}=\mathrm{y}=$ 0.08 . Accordingly, the spontaneous polarization in case of $\mathrm{x}=\mathrm{y}=0.08$ composition was found to be maximum with a value of $10.83 \mu \mathrm{C} / \mathrm{cm}^{2}$. However, the maximum value of coercive field i.e. $\mathrm{E}_{\mathrm{c}}=15.11 \mathrm{kV} / \mathrm{cm}$ was obtained for $\mathrm{x}=\mathrm{y}=0.02$ mole $\%$.

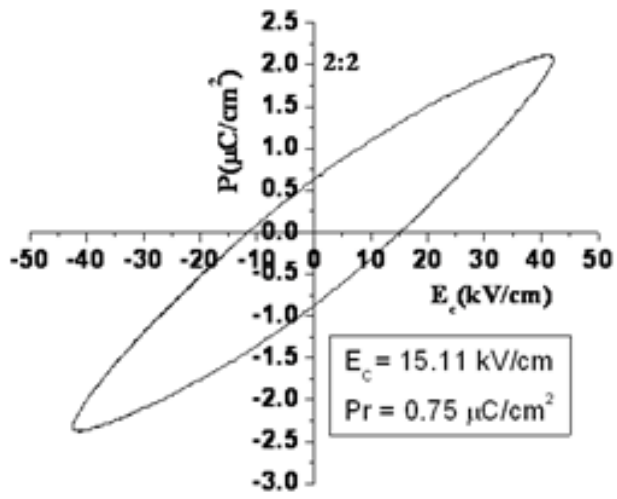

(a)

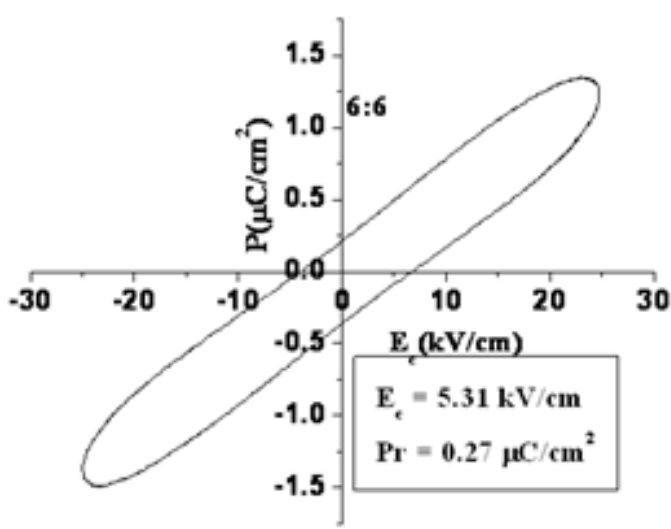

(b)

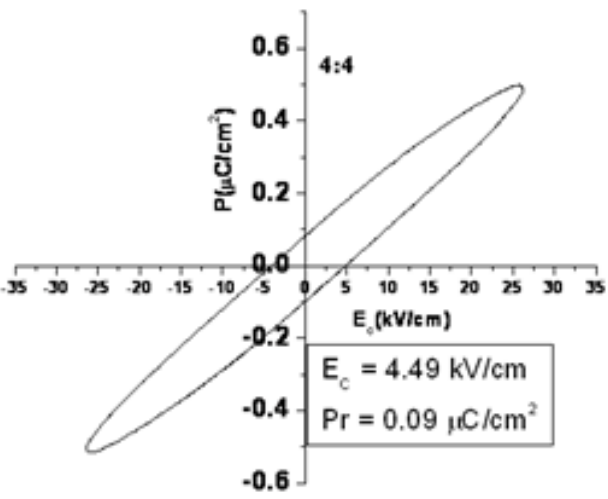

(b)

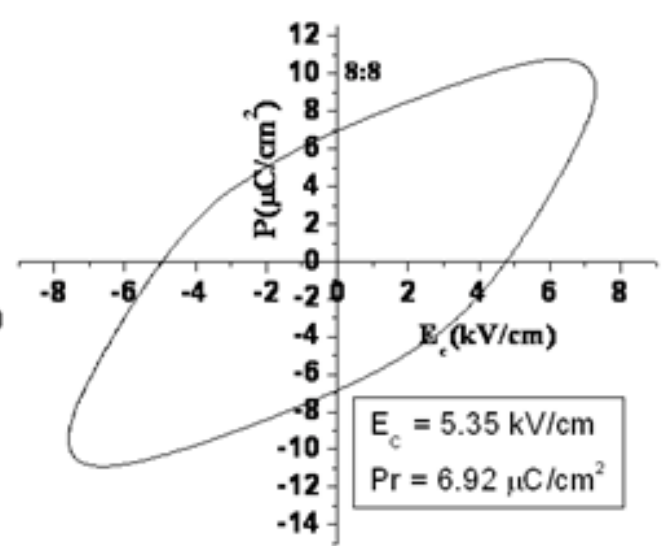

(d)

Fig. 6 Polarization versus electrical field (P - E) Loop for rare earth double doped lead titanate with composition (a) $x=y=2 \%$, (b) $x=y=4 \%$, (c) $x=y=6 \%$ and (d) $x=y=8 \%$ 
Structural, dielectric, piezoelectric and ferroelectric behavior of rare earth double doped ....

Table 3 Values of coercive field $\left(E_{c}\right)$ remnant polarization $\left(P_{r}\right)$ and spontaneous polarization $\left(P_{s}\right)$ for rare earth double doped lead titanate with compositions $\operatorname{Pb}_{1-x} \operatorname{Pr}_{x} \operatorname{Ti}_{1-y} Y_{y} O_{3}$ where $x=y=0.02,0.04,0.06$ and 0.08

\begin{tabular}{|lccc|}
\hline $\begin{array}{l}\mathrm{x}=\operatorname{Pr} \\
\mathrm{y}=\mathrm{Y}\end{array}$ & $\begin{array}{c}\text { Coercivity } \\
(\mathrm{kV} / \mathrm{Cm})\end{array}$ & $\begin{array}{c}\text { Remanance Polarization } \\
\left(\mu \mathrm{C} / \mathrm{cm}^{2}\right)\end{array}$ & $\begin{array}{c}\text { Spontaneous Polarization } \\
\left(\mu \mathrm{C} / \mathrm{cm}^{2}\right)\end{array}$ \\
\hline $\begin{array}{l}\mathrm{x}=0.02, \\
\mathrm{y}=0.02\end{array}$ & 15.11 & 0.75 & 2.22 \\
$\mathrm{x}=0.04$ & 4.49 & 0.09 & 0.51 \\
$\mathrm{y}=0.04$ & & 0.27 & 1.41 \\
$\mathrm{x}=0.06$, & 5.30 & 6.92 & 10.83 \\
$\mathrm{y}=0.06$ & 5.35 & & \\
$\mathrm{x}=0.08$, & & & \\
$\mathrm{y}=0.08$ & & & \\
\hline
\end{tabular}

\section{Conclusion}

Rare earth i.e., praseodymium and yttrium doped lead titanate having ferroelectric and piezoelectric application was synthesized successfully using conventional solid state reaction technique at sintering temperature of $1100^{\circ} \mathrm{C}$. X-ray diffraction pattern indicates single phase formation with perovskite type tetragonal structure. The c/a ratio decreases with increase in the amount of praseodymium and yttrium content. Dielectric constant for all the composition shows depends on frequency and temperature. The highest value of dielectric constant (5440) was observed in case of $\mathrm{x}=\mathrm{y}=8 \mathrm{~mole} \%$ of praseodymium and yttrium doping. However, $4 \mathrm{~mole} \%$ of dopant composition shows ideal Curie - Weiss behavior, whereas other composition shows diffused phase transition. The value of piezoelectric charge coefficient $\left(\mathrm{d}_{33}\right)$ increases from 26 to $54 \mathrm{pCN}^{-}$ ${ }^{1}$. Ferroelectric properties show significant composition dependence. The maximum value of remnant and spontaneous polarization was found to be 6.920 and $10.83 \mu \mathrm{C} / \mathrm{cm}^{2}$ for $\mathrm{x}=\mathrm{y}=8 \mathrm{~mol} \%$. Hence, maximum dielectric constant with maximum remnant and spontaneous polarization was found in case of 8 mole $\%$ dopant composition of praseodymium and yttrium.

\section{Acknowledgement}

The author's are thankful to Instrumentation Centre, Indian Institute of Technology, Roorkee for providing XRD and electron microscopic facilities. The author's are also thankful to Dr. Binay Kumar of Department of Physics \& Astrophysics, University of Delhi, Delhi for providing piezoelectric and ferroelectric facilities of his laboratory.

\section{References}

[1]. T. Takahashi, Lead titanate ceramics with large piezoelectric anisotropy and their applications, Ceram. Bull. 69 (4) (1990) 691-695

[2]. K. Hashimoto, T. Tsurutra, Morinaka, N. Yoshiik, High performance human information sensor, Sensors and Actuators 79 (2000) 46-52

[3]. Y. Yamashita, K. Yokoyama, H. Honda, T. Takahashi, $(\mathrm{Pb}, \mathrm{Ca})\left(\left(\mathrm{Co}_{1 / 2} \mathrm{~W}_{1 / 2}\right), \mathrm{Ti}\right) \mathrm{O}_{3}$ piezoelectric ceramics and their applications, Jpn. J. Appl. Phys. 20 (1981) 183-187

[4]. [J. Shenglin, Z. Xuili, W. Xiaozhen, W. Xianghong, Investigation on anisotropy in piezoelectric properties of modified PbTiO3 ceramics, Piezoelectr Acoust. 17 (1995) 26-29

[5]. K. Okazaki, K. Takahashi, Memo. National Defense Acad. 5 (1997) 183

[6]. I. Ueda, I. Ikegama, Piezoelectric properties of modified $\mathrm{PbTiO}_{3}$ ceramics, Jpn. J. Appl. Phy.7 (1968) 236-242

[7]. L. Hanh, S. Nomura, Proc. IST Meeting Ferroelectric Mat. Appl (FMA - 1) Kyoto, Japan (1977) 315

[8]. S. Chu, C. Chen, Effects of dopants on the piezoelectric and dielectric properties of Sm-modified $\mathrm{PbTiO}_{3}$ ceramics, Mat. Res. Bull, 35 (2000) 2317-2324

[9]. K. K. Deb, Pyroelectric characteristics of $\left(\mathrm{Pb}_{0.9} \mathrm{Sm}_{0.1}\right) \mathrm{TiO}_{3}$ ceramics, Ferroelectrics, 82 (1988) 45-53

[10]. R. Tickoo, R.P.Tandon, K.K.Bamzai, P.N.Kotru, Dielectric and piezoelectric characteristics of samarium modified lead titanate ceramics, Mat. Sci., Eng. B 103(2003) 145-151

[11]. Vishal Singh, K.K. Bamzai, Shivani Suri, Nidhi, Structural and electrical characterization of praseodymium modified lead titanate, Ceram. Int. 37 (2011) 2655-2662

[12]. P. Duran, J. F. Fdezlozano, F. Capel, C. Moure, Large electromechanical anisotropic modified lead titanate ceramics, J. Mat. Sci., 23 (1988) 4463-4469

[13]. P.A. Shikh, R.C. Kambale, A.V. Rao, Y.D. Kolekar, Comparative studies on structural and electrical properties of lead titanate synthesized by ceramic and co-precipitation method, J. Alloys and Compounds, 486 (2009) 442-446

[14]. S. M. Pilgrim, Diffuseness as a useful parameter for relaxor ceramics, J. Am. Ceram. Soc., 73 (1990) 3122-3125

[15]. K. Prasad, Diffuse phase transition in pervoskite ferroelectrics, Indian J. Eng. Mater.sci. 7 (2000) 446-450

[16]. J. D. Frutos, B. Jimenez, Evolution of the spatial distribution of polarization in lead-calcium ferroelectric ceramics, Ferroelectrics, 126 (1992) 341-345 